\section{Saphenous sparing laser modern options (comment to Gianesini et al., Veins and Lymphatics 2013;2:e21 and Veins and Lymphatics 2015;4:5246)}

\section{Enrique Luis Ferracani}

\section{Private CVS surgeon, former chief of} Navy Hospital, Argentina

\section{Dear Editor}

In your journal I really liked reading the papers by Gianesini et al. Short endovenous laser ablation of the great saphenous vein in a modified CHIVA strategy, ${ }^{1}$ and Laser-assisted strategy for reflux abolition in a modified CHIVA approach. ${ }^{2}$

Saphenous sparing procedures demonstrated competitive results whenever compared with ablative ones. ${ }^{3,4}$

For this reason, in the last years I also experimented an innovative laser procedure with the aim of sparing the saphenous vein.

The strategy is to reduce the enlarged great saphenous vein calibre by creating only partially shrunk rings of decreased calibre in the preterminal valve region of the great saphenous vein and then every $5 \mathrm{~cm}$ downward, covering a total length of $20 \mathrm{~cm}$ (Figure 1). The procedure is performed by a $1470 \mathrm{~nm}$ laser.

Neither crossectomy nor total vein occlusion is done. In this way it is possible to spare the drainage of the junctional tributaries and to avoid the Receck paradox concerning the post-procedural network predisposition to recurrence. ${ }^{5}$

Phlebectomy of the incompetent tributaries along the leg completes the procedure.

The rings of decreased calibre constitute an area of increased resistance, so counteracting the reflux coming from the incompetent junction during the diastole. During the muscular systole the flow accelerates through the reduced calibres following the Castelli law, consequently reducing the shear stress and thus the inflammation on the vessel wall.

Technically these rings are created delivering $24 \mathrm{~J} / \mathrm{cm}$.

Up to now we treated 17 patients $\left(\mathrm{C}_{2}\right.$ ${ }_{4}$ EpAsPr) presenting an incompetent saphenofemoral junction and a great saphenous vein reflux, with a great saphenous vein junctional calibre greater than $6 \mathrm{~mm}$.

In a 3 years follow up we experienced 2 recurrences due to a hunterian and anterior accessory sapheonus vein incompetence. In all the other patients the sapheonus calibre remained reduced without any detectable reflux.

The procedure is performed in an operating room, under sedation but without tumescence.
We deliver $4 \mathrm{~W}$ for $6 \mathrm{~s}$, never increasing the leed over $24 \mathrm{~J} / \mathrm{cm}$ in order to avoid an excessive damage of the wall.

After every ring shrunk a sonographic check is performed. The targeted percentage reduction is $50 \%$ of the pre-operative calibre.

Following our oral presentation at the $\mathrm{XV}$ Pan American Congress of Phlebology and Lymphology of Lima Peru on May 13, 2012, our work was awarded with the $1^{\text {st }}$ prize of the XX Argentine and International Phlebology Congress SAFYL 2013. We presented our preliminary experience also at the XVII World Congress of the UIP Boston 2013 and published the pilot study on the Journal of Phlebology of the Argentinean Society. ${ }^{6}$
Correspondence: Enrique Luis Ferracani, Private CVS surgeon, former chief of Navy Hospital, Argentina.

E-mail: eferracani@gmail.com

Key words: Letter to editor; saphenous sparing procedures.

Received for publication: 30 September 2015. Accepted for publication: 30 September 2015.

This work is licensed under a Creative Commons Attribution 3.0 License (by-nc 3.0).

(C) Copyright E.L. Ferracani, 2015

Licensee PAGEPress, Italy

Veins and Lymphatics 2015; 4:5531

doi:10.4081/vl.2015.5531

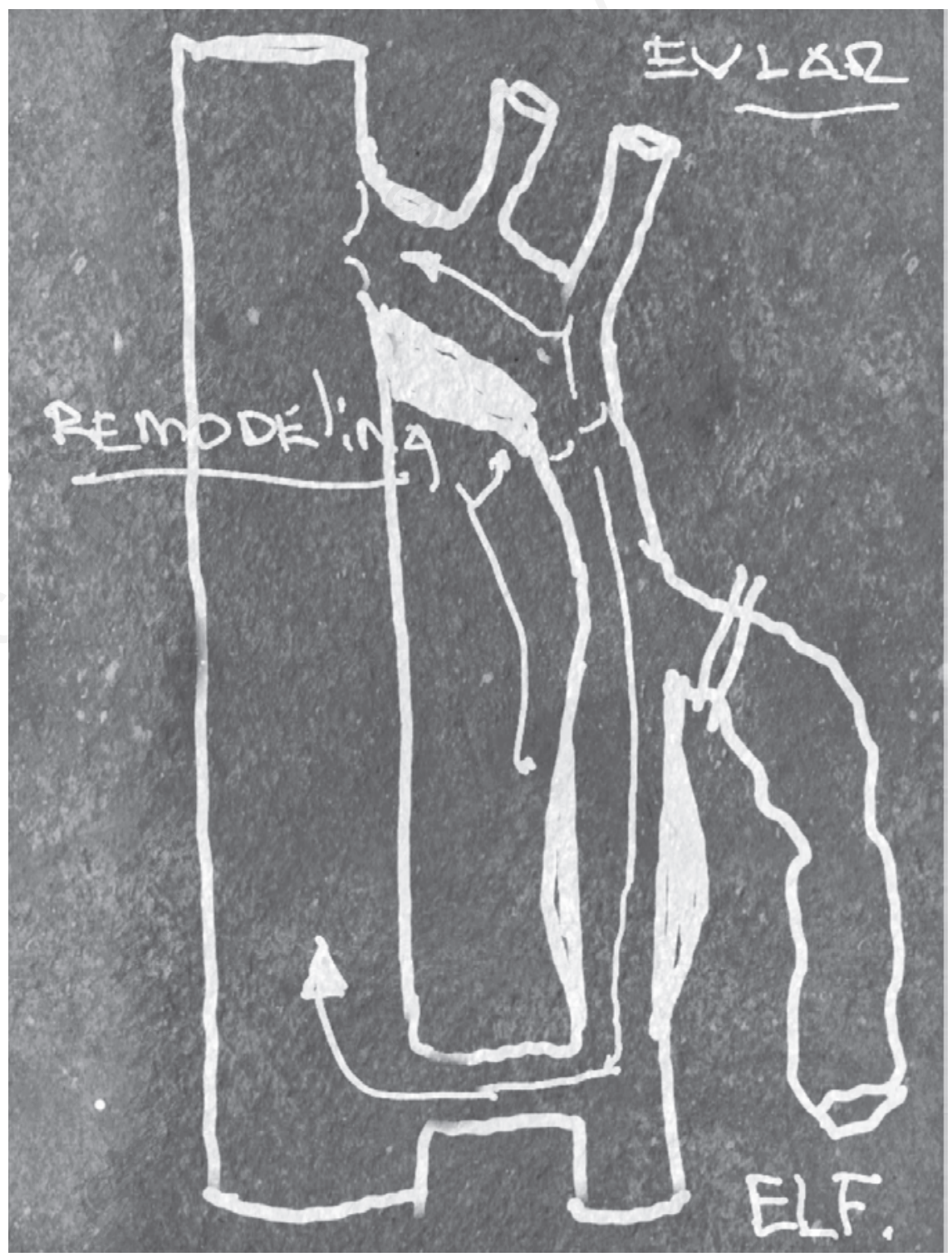

Figure 1. Rings of calibre reduction favoring a systolic anterograde flow and a diastolic retrograde draining flow into a re-entry perforator. 
in a modified CHIVA approach. Veins and Lymphatics 2015;4:5246.

\section{References}

1. Gianesini S, Menegatti E, Zuolo M, et al. Short endovenous laser ablation of the great saphenous vein in a modified CHIVA strategy. Veins and Lymphatics 2013; 2:e21.

2. Gianesini S, Menegatti E, Zuolo M, et al. Laser-assisted strategy for reflux abolition
3. Carandina S, Mari C, De Palma M, et al. Varicose vein stripping vs haemodynamic correction (CHIVA): a long term randomised trial. Eur J Vasc Endovasc Surg 2008;35:230-7.

4. Bellmunt-Montoya S, Escribano JM, Dilme J, Martinez-Zapata MJ. CHIVA method for the treatment of chronic venous insuffi- ciency. Cochrane Database Syst Rev 2015;6:CD009648.

5. Cestmir R. The hemodynamic paradox as a phenomenon triggering recurrent reflux in varicose vein disease. Int $\mathrm{J}$ Angiol 2012;21:181-6.

6. Ferracani E. Internal laser valvuloplasty and venous remodeling using 1470laser. Initial experience. Flebologia 2013;3:39-40. 